\title{
Comparative egg attendance patterns of incubating polar petrels
}

\author{
Scott A. Shaffer ${ }^{1 *} \mathbb{0}$, Pierre Blévin ${ }^{2,3}$, Christophe Barbraud ${ }^{2}$, Olivier Chastel ${ }^{2}$ and Henri Weimerskirch²
}

\begin{abstract}
Background: The internal environment of eggs in most birds is regulated by transferring heat energy through contact incubation, maintaining nest microclimate, and frequent egg turning by the incubating parent on its nest. However, we lack information about egg attendance patterns in birds that breed in polar environments where variations in life history are expected to influence incubation behavior. Moreover, crevice/burrow nesting petrels in high-latitude regions are known for periodically leaving their egg unattended (hereafter 'egg neglect'), but there is little reporting on the internal condition of unattended eggs. At Dumont d'Urville Station, Antarctica, we studied the incubation behavior of 24 snow (Pagodroma nivea) and 15 Cape (Daption capense) petrel pairs using egg loggers that recorded egg turning rates, orientation changes, and temperatures at $1 \mathrm{~Hz}$ for durations of 3-6 days.

Results: Egg turning frequency ( $1.31 \pm 0.33$ vs. $1.38 \pm 0.39$ turns $^{-1}$ ), angle change per turn ( $43.1 \pm 43.2$ vs. $48.6 \pm 43.7^{\circ}$ turn $\left.^{-1}\right)$, and egg temperature $\left(34.1 \pm 2.3\right.$ vs. $34.1 \pm 2.0^{\circ} \mathrm{C}$ ) were nearly identical for snow and Cape petrels, respectively. However, egg neglect was only observed in snow petrel nests (based on egg temperature changes) where loggers recorded mean durations of $1.34 \pm 1.15$ days (maximum duration of 3.63 days). During periods of neglect, eggs cooled to $5.5 \pm 1.8^{\circ} \mathrm{C}$ over an average of $91 \mathrm{~min}$, but were rewarmed by parents in only $76 \mathrm{~min}$ at a rate of $0.33^{\circ} \mathrm{C} \mathrm{min}^{-1}$.

Conclusions: Egg temperatures of both species during regular incubation were within $1-2^{\circ} \mathrm{C}$ of other high-latitude petrel species, but neglected snow petrel eggs remained several degrees above freezing, which was likely attributed to crevice nesting where neglected eggs are buffered by environmental conditions. Using egg rewarming rates, thermal capacity of eggs, and published metabolic rates, we estimate egg rewarming costs in snow petrels to be 1.5 to $1.9 \times$ BMR. Excluding egg neglect periods, turning rates for both petrel species were lower than other seabirds studied using biologging devices, which may be associated with the prolonged incubation periods that are characteristic of procellariiform seabirds.
\end{abstract}

Keywords: Biologging, Cape petrel, Egg turning rates, Egg temperatures, Egg neglect, Snow petrel

\section{Background}

For most avian species, the internal environment of eggs is regulated by incubation patterns of adults involving the transfer of heat energy through contact incubation, maintenance of a nest microclimate, and frequent egg

*Correspondence: scott.shaffer@sjsu.edu

1 Department of Biological Sciences, San Jose State University, One Washington Square, San Jose, CA 95192-0100, USA

Full list of author information is available at the end of the article turning [1]. Egg turning facilitates heat exchange across all surfaces of the egg or among a brood of eggs when eggs are redistributed around the nest [2, 3]. Egg turning also prohibits albumen inside the egg from stratifying, thereby enhancing protein and water uptake by the embryo [4-6]. Cumulatively, these egg attendance behaviors of incubating birds are essential for egg hatching, chick development, and brood viability in the majority of non-megapode species (reviewed in $[5,7]$ ). 
Although heat input and egg turning are required during incubation in most birds, some species leave their nests unattended for periods of hours to days [813]. These 'recesses' by incubating parents are generally thought to be used for self-maintenance or to avoid predation of the incubating bird [9-11, 14-17]. Nevertheless, the effect of egg cooling temporarily slows or suspends embryonic development until incubation is resumed [18-20]. Recesses lasting several days (hereafter 'egg neglect') are known to occur in crevice or burrow nesting seabirds, but few studies have reported the temperatures of eggs or nesting chamber environment during periods of neglect $[9,16,17,20,21]$. However, using artificial biologging eggs integrated with thermistors and orientation sensors (e.g., [22-26]), it is possible to characterize the lack of turning and rates of cooling when eggs are neglected, contrasted by the behaviors of parents during egg rewarming when incubation resumes. The timing and duration of these events as well as minimum egg temperatures compared to the temperature of eggs incubated without interruptions can also be quantified. These data can improve our understanding of the environmental conditions that eggs are subjected to when neglected, especially for species that breed in extreme environments where variations in life history are expected to influence egg attendance patterns of adults.

Fulmarine petrels are tubenose seabirds (family Procellariidae) that breed in high-latitude regions, especially the polar environment in both hemispheres [27]. Within this group, snow (Pagodroma nivea) and Cape (Daption capense) petrels breed sympatrically at colonies around the Antarctic continent [27-30]. Like all procellariiform seabirds, parents' alternate incubation duties of a single egg [27], but snow petrels nest in crevices under boulders on rocky slopes, whereas Cape petrels nest in the open on slope faces [31-33]. Both species exhibit similar incubation durations (45 vs. 47 days [34-36], respectively), but snow petrels are known to use egg neglect [37-40], which is not common in Cape petrels. We hypothesize that crevice nesting allows snow petrels to periodically neglect their eggs because eggs are protected from aerial predators and extreme weather conditions. Given that one species neglects its eggs periodically, yet incubation durations are so similar, we predict that egg temperatures and turning frequencies differ as a possible mechanism to compensate for egg neglect periods in snow petrels. Thus, our objectives were to compare the egg attendance patterns of snow and Cape petrels using biologging eggs that measured turning rates, 3-D angle changes, and core egg temperatures with the ability to evaluate egg neglect events [26, 41-43]. In addition to characterizing the internal state of neglected eggs, we also compared egg temperatures during regular incubation periods in both species to published data on other seabirds to evaluate whether substantive differences exist for breeders in a polar environment.

\section{Methods \\ Field site and study species}

Snow and Cape petrels were studied during the austral summer (19 December 2013 through 12 January 2014) at Pointe Géologie, Dumont d'Urville Station, Antarctica $\left(66.7^{\circ} \mathrm{S}, 140.0^{\circ} \mathrm{E}\right)$. Adult petrels were incubating a single egg in either a rocky crevice (snow petrels) or a surface nest (Cape petrels) on rocky ice-free cliff faces that were accessible for monitoring. Each nest was individually identified with temporary paint markings sprayed on nearby rocks at one of five sub-colonies monitored annually since 1963 [31, 44, 45]. All snow petrel nests were checked a minimum of four times throughout the season to evaluate nest occupancy, egg lay date, and hatching and fledging success. Study nests were checked more frequently as described below.

\section{Egg loggers}

Artificial eggs containing a datalogger were used to record egg turning patterns and core egg temperature in the nests of each species (see $[26,42,43]$ for details). Each egg was made of plastic formed in a mold that produced eggs similar in size $(40 \mathrm{~mm}$ breadth $\times 57 \mathrm{~mm}$ length), shape, and color to the petrel eggs (Fig. 1). The data loggers (with $4.2 \mathrm{~V}, 340 \mathrm{mAh}$ LiPo battery) weighed approximately $25 \mathrm{~g}$ and were oriented along the long axis of the egg (see Fig. 2S in [26]) inside a tube attached to the inside of the egg. Additional mass was added to each

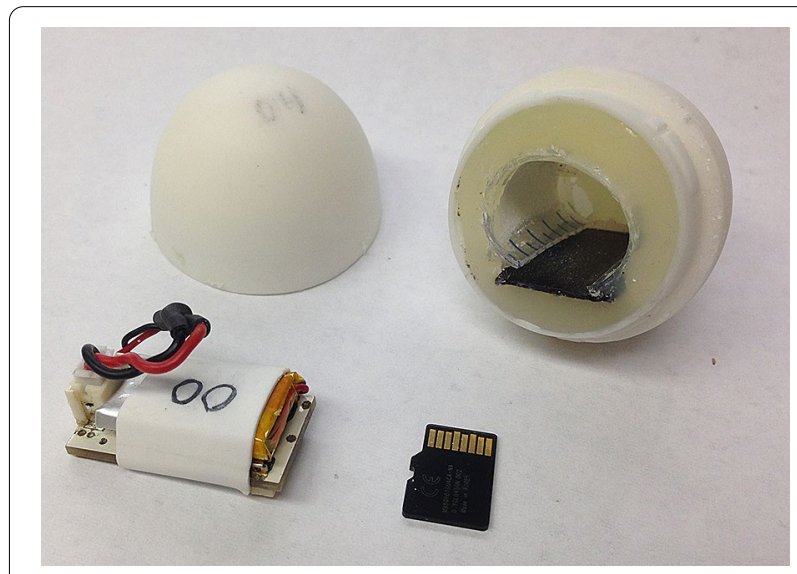

Fig. 1 Photo of artificial egg, data logger, and microSD flash memory card used to measure egg turning behavior and incubation temperatures of snow and Cape petrels. Eggs were made of molded plastic ( $40 \mathrm{~mm}$ breadth $\times 57 \mathrm{~mm}$ length) and both halves were filled with barite powder to add mass to the approximate mass of petrel eggs. Photo by S.A. Shaffer 
egg to approximate the mass of real petrel eggs. This was achieved by packing each egg with dry barite $\left(\mathrm{BaSO}_{4}\right)$ powder (specific gravity of $4.5 \mathrm{~g} \mathrm{~cm}^{-3}$ ) around the egg logger. Prior to deployment, egg loggers were activated, then sealed in the egg by threading both halves of the artificial egg together. A small amount of adhesive was applied around the seam of both egg-shell halves to secure the egg and to minimize moisture intrusion.

Each data logger was a microprocessor-based unit containing a triaxial accelerometer $\left(1 \mathrm{e}-4 \mathrm{~m} \mathrm{~s}^{-2}\right.$ resolution) and triaxial magnetometer $(0.2 \mu \mathrm{T}$ resolution) to measure egg orientation in three dimensions (i.e., roll, pitch, and yaw) with respect to the Earth's magnetic field. There was a single temperature thermistor on each logger that measured core egg temperature $\left(0.125{ }^{\circ} \mathrm{C}\right.$ resolution). All three sensors recorded a measurement to a removeable microSD card every second for the duration of its deployment $[26,42,43]$.

\section{Egg logger deployments}

Each single egg was removed from its nest and replaced by an egg logger. Eggs were swapped by hand without removing the parent bird from its crevice or nest. Snow petrels remained in their burrows and typically resumed incubation within 20-30 min (often less) as revealed by the sensors in the artificial eggs. Cape petrels remained on the nest while eggs were swapped slowly by hand. Each real egg removed from a nest was labeled (written in pencil) and placed into a padded and insulated container for transport back to the station. Elapsed time between egg removal from the nest and placement into an incubator was less than $60 \mathrm{~min}$. Before placing eggs into the incubator, eggs were weighed $( \pm 1 \mathrm{~g})$ and maximum length and breadth were measured with calipers $( \pm 0.1 \mathrm{~mm})$. Eggs were also candled with a flashlight to determine fertility status by the presence of blood vessels branching from the yolk.

Real eggs were turned by hand with variable rotations every $3-4 \mathrm{~h}$ and turning direction was reversed at each turning event. The incubator was kept at a constant temperature of $39^{\circ} \mathrm{C}$ and humidity was maintained by evaporation of water placed in a dish inside the incubator.

The occupancy of each crevice nest (i.e., snow petrels) was checked daily by visual inspection from 1 to $3 \mathrm{~m}$ from the crevice entrance or by listening for threat calls from the nest occupant. When neither confirmed occupancy, the nest was searched to find the artificial egg and determine its status (i.e., warm or cold to touch). Because Cape petrels are surface nesters, visual inspections were conducted by sighting the occupants of the nests from 4 to $5 \mathrm{~m}$ away.

After 3-6 days, egg loggers were removed from each nest and the real egg returned to its original nest in the same manner as deployment. Nest occupancy was checked visually or by threat call, 2-3 days after egg return and then several weeks later to ascertain hatching success. The hatching success of unmanipulated nests was determined as part of the annual long-term population monitoring described earlier. In either case, hatching success was verified by the presence of (1) a chick, (2) large egg shell and/or membrane fragments, (3) an abandoned egg, or (4) no egg with a confirmed lay date.

\section{Data processing and statistics}

Data recovered from each logger was processed using purpose-built codes written in MATLAB 2016b (The MathWorks, Natick, MA, USA) following methods described in $[26,42,43]$. In brief, accelerometer and magnetometer measurements were converted to 3-2-1 Euler angles expressed as yaw, pitch, and roll. We only considered angular changes greater than $10^{\circ}$ as an egg turning event [26] for which we determined the start, stop, angular change, and duration between turning and stationary events.

Given the resolution of temperature thermistors $\left(0.125^{\circ} \mathrm{C}\right)$, egg logger temperature data were smoothed using a running average that included 5000 points per step through the data. Egg neglect periods were identified by the initiation of a continuous drop in egg temperature below $26^{\circ} \mathrm{C}$ ('physiological zero' [7]), for periods exceeding $2-3 \mathrm{~h}$ when eggs reached constant cool temperatures and there was a lack of egg turning activity (Figs. 2b, 3). Egg neglect events ended when there was a clear increase in egg temperature and egg turning activity resumed. To evaluate the trends in egg cooling and rewarming for snow petrels, we calculated the duration of an egg neglect period (start of cooling to the start of rewarming), cooling and rewarming times, and the approximate rates of each, respectively.

For all egg logger deployments, the first 120 min after egg logger deployment and the last 120 min prior to egg logger retrieval were excluded from data analyses to account for any disturbance to parents during our activity in the colonies [26].

Ambient air temperatures and general weather conditions were monitored daily by the Météo-France service at Dumont d'Urville Station. For the purposes of this study, we only report the minimum, mean, and maximum daily air temperatures because they reflect weather conditions around the base and not specifically in the colonies ( $\sim 0.5 \mathrm{~km}$ away).

All data analyses including statistical comparisons were conducted using purpose-built scripts or native functions within the Optimization, and Statistics and Machine Learning Toolboxes in the programming environment MATLAB 2016b (The MathWorks, Natick, MA, USA). 

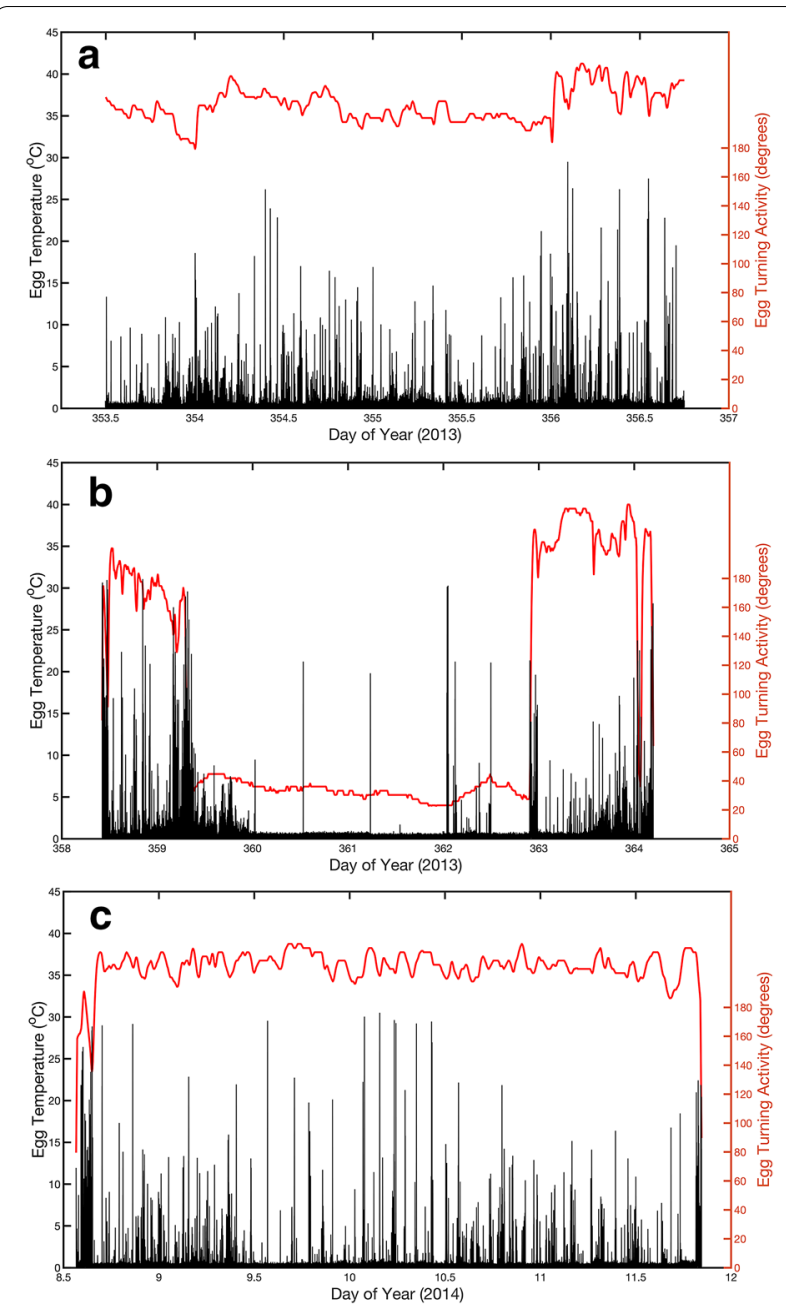

Fig. 2 Comparative egg temperature and turning activity in a a snow petrel nest without egg neglect, $\mathbf{b}$ snow petrel nest with egg neglect, and $\mathbf{c}$ Cape petrel nest. Birds incubated artificial eggs with data loggers containing sensors to measure turning activity (black lines) and core egg temperatures (red lines). In $\mathbf{b}$, egg neglect was denoted by a drop in egg temperature and lack of turning activity over 4 days. There was unexplained turning activity (spikes) that may have resulted from periodic visits by a parent to check the egg

Mean values between or within a species were compared using $t$-tests or ANOVA's where appropriate and linear mixed effects models were used in comparisons with unequal sample sizes (i.e., differences in logger deployment duration) between study nests [46]. All data are presented as mean \pm SD unless otherwise stated and statistical significance used for testing comparisons was $\alpha<0.05$.

\section{Results}

A total of 50 egg logger deployments were conducted over 6 weeks of fieldwork. This included 29 snow petrel nests and 21 Cape petrel nests. A check of fertility status on the date of egg removal from a nest revealed that $82 \%$ (23 eggs) of snow petrel eggs and $86 \%$ (18 eggs) of Cape petrel eggs were fertile. On average, snow petrel eggs were approximately $17 \pm 6$ days old $(37 \pm 14 \%$ through cycle) and Cape petrel eggs were approximately $25 \pm 4$ days old ( $53 \pm 9 \%$ through cycle) at the start of our study. Five snow petrel eggs (including one fertile egg) addled in the incubator and were discarded. All remaining eggs (regardless of viability) of both species were returned to their original nests. For snow petrels, only 8 of $22(36.4 \%)$ fertile eggs hatched and none were from nests with observed egg neglect. There were an additional 163 snow petrel nests with eggs at the start of the breeding season and of these, 60 nests successfully hatched. The hatching success of Cape petrel nests was not determined because investigators departed the station prior to hatching. However, daily nest checks revealed that all birds continued to incubate their eggs up to 4 days after original eggs were returned to their nests.

Morphometric measurements of petrel eggs are given in Table 1. Egg loggers deployed in snow petrel nests weighed $44.5 \pm 1.9 \mathrm{~g}$, which was about $19 \%$ lighter than eggs removed from corresponding nests (Table 1). Similarly, egg loggers deployed in Cape petrel nests weighed $46.2 \pm 2.0 \mathrm{~g}$, which was approximately $21 \%$ lighter than eggs removed from corresponding nests.

Of the 50 egg loggers deployed, only 39 yielded data used in analyses. Data from the remaining loggers were excluded for one or more of following reasons: (1) logger failure, (2) the egg came apart in a nest, (3) water intrusion from snow melt around several Cape petrel nests, or (4) in one case, the egg logger in a snow petrel nest was depredated (likely by a south polar skua, Stercorarius maccormicki). Thus, viable data were obtained from 24 (of 29) snow petrel nests and 15 (of 21) Cape petrel nests. Mean egg logger deployment duration was $3.62 \pm 1.13$ days in snow petrel nests and $3.42 \pm 0.48$ days in Cape petrel nests.

After removing periods of egg neglect (see below), egg temperatures were identical in both species. Mean snow petrel egg temperature was $34.1 \pm 2.3{ }^{\circ} \mathrm{C}(N=24$ eggs $)$ and was $34.1 \pm 2.0^{\circ} \mathrm{C}(N=15$ eggs $)$ for Cape petrel eggs (Fig. 2). Similarly, mean maximum egg temperatures of snow petrels was $38.1 \pm 1.9^{\circ} \mathrm{C}(N=24$ eggs $)$ and was $38.8 \pm 1.5^{\circ} \mathrm{C}(N=15$ eggs $)$ for Cape petrel eggs. There were no distinguishable trends in egg temperature variation associated with a circadian cycle in either species (see examples in Fig. 2).

No occurrences of egg neglect were observed in Cape petrels, but we identified egg neglect in seven snow petrel nests where mean duration of egg neglect was $1.34 \pm 1.15$ days ( $\max 3.63$ days). We observed nine instances of egg cooling after egg loggers were left 


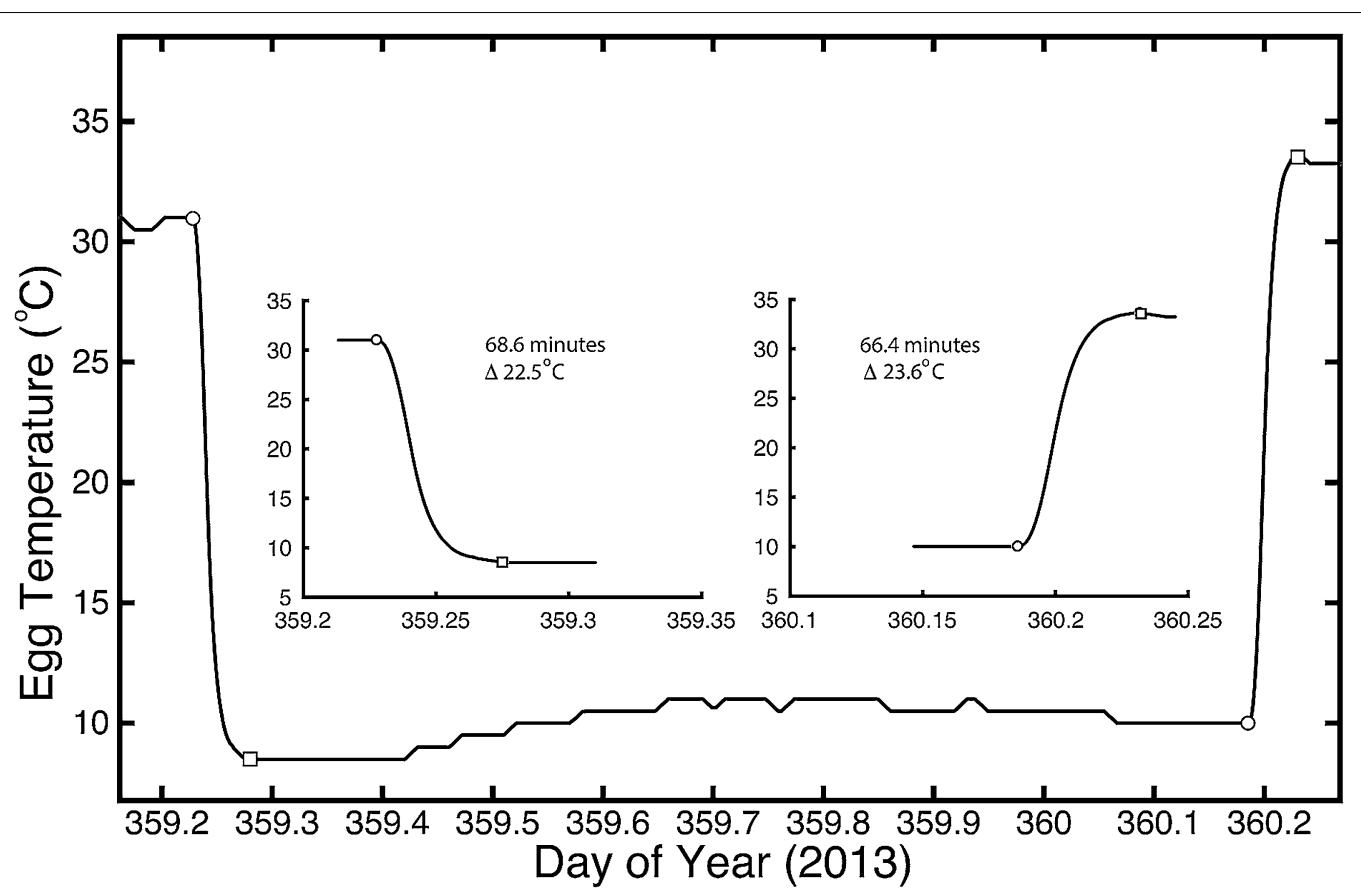

Fig. 3 Example plot showing a 1-day (22.9 h) period of egg neglect for snow petrel 13. Inset figures show zoomed images of egg cooling and rewarming. Measurements of time to cool or rewarm were determined by the elapsed time between the starting (circle) and ending points (square). Shown in each inset is the elapsed time and temperature change for each phase. Summarized data for all events recorded are shown in Table 2. The ambient air temperature over this 1 -day period was $1.3^{\circ} \mathrm{C}\left(\min -2.2^{\circ} \mathrm{C}\right.$, max $\left.3.0^{\circ} \mathrm{C}\right)$

Table 1 Morphometric measurements of snow and Cape petrel eggs at Dumont d'Urville Station, Antarctica

\begin{tabular}{lllll}
\hline Species & Eggs $(\boldsymbol{N})$ & Mass $(\mathbf{g})$ & Breadth $(\mathbf{m m})$ & Length $(\mathbf{m m})$ \\
\hline Snow petrel & $28^{\text {a }}$ & $55.4 \pm 5.7$ & $42.1 \pm 1.8$ & $60.3 \pm 2.4$ \\
(min, max) & & $(42.0,66.0)$ & $(36.8,44.9)$ & $(55.2,65.0)$ \\
Cape petrel & 21 & $58.7 \pm 5.0$ & $43.4 \pm 1.5$ & $62.5 \pm 2.2$ \\
(min, max) & & $(48.0,67.0)$ & $(39.2,45.6)$ & $(58.0,66.0)$ \\
\hline
\end{tabular}

Breadth is the widest part of the egg and length is the maximum length. All values are means $\pm S D$

${ }^{\text {a }} 28$ eggs from 29 nests because one egg was found cracked and not measured unattended and eight instances of egg rewarming after a parent resumed incubation (Table 2). These periods of egg neglect were confirmed by the absence of an adult in nest crevices during daily nest checks. Overall, the duration for egg loggers to cool to a steady state after being left alone was longer but not significantly so $\left(F_{1,15}=1.04, P=0.324\right)$ than the duration for egg loggers to be rewarmed by snow petrel parents (Table 2, Fig. 3). The total change in egg logger temperature associated with cooling or rewarming was $23-24{ }^{\circ} \mathrm{C}$ (Table 2), but the mean minimum egg logger temperature during egg neglect was $5.5 \pm 1.8{ }^{\circ} \mathrm{C}$ ( $N=9$ events), which was warmer than mean daily air temperatures $\left(0.9 \pm 1.9{ }^{\circ} \mathrm{C}\right.$,

Table 2 Egg cooling and re-warming parameters (mean \pm SD) of snow petrels incubating artificial eggs containing data loggers during the austral summer of 2013-2014 at Dumont d'Urville Station, Antarctica

\begin{tabular}{|c|c|c|c|c|}
\hline Egg condition & $N$ & Elapsed time (min) & $\Delta T\left({ }^{\circ} \mathrm{C}\right)$ & Rate of $\Delta T\left({ }^{\circ} \mathrm{C} \min ^{-1}\right)$ \\
\hline Cooling & 9 & $90.9 \pm 29.3$ & $-23.0 \pm 4.3$ & $-0.27 \pm 0.08$ \\
\hline$(\min , \max )$ & & $(67.1,146.3)$ & $(-12.8,-26.6)$ & $(-0.18,-0.40)$ \\
\hline Re-warming & 8 & $75.8 \pm 32.1$ & $23.7 \pm 6.4$ & $0.33 \pm 0.10$ \\
\hline (min, max) & & $(43.7,148.7)$ & $(12.2,32.3)$ & $(0.19,0.45)$ \\
\hline
\end{tabular}

$N$ is the number of egg cooling or re-warming events recorded from seven petrel nests. Elapsed time represents the duration of egg cooling or re-warming based on measured temperature changes to a steady state. $\Delta T$ represents the total change in temperature of the egg and rate of $\Delta T$ is provided for simple comparison between conditions. However, eggs cooled and re-warmed in a curvilinear manner (see Fig. 3) 
$\min -4.1{ }^{\circ} \mathrm{C}, \max 7.9{ }^{\circ} \mathrm{C}$ ) measured at the station over the study period (Fig. 4).

Egg loggers left unattended in snow petrel nests were excluded from evaluation of egg turning parameters. Hourly egg turning rates were not significantly different between species (Table $3 ; F_{1,27}=0.286, P=0.597$ ) and given the lack of variation in daylength (i.e., $24 \mathrm{~h}$ of daylight), there was no discernable pattern in egg turning associated with a circadian cycle (Fig. 2). Although hourly turning rates were not statistically different between species, the angle that egg loggers were turned at each turning event was $5.5^{\circ}$ greater (mixed-effect model; $\left.F_{1,3875}=15.2, P<0.001\right)$ in Cape petrel nests compared to snow petrels (Table 3, Fig. 2). Mean elapsed time between egg turning events in snow petrels was 6.5 min shorter, but not statistically different $\left(F_{1,27}=2.03, P=0.166\right)$ from that of Cape petrels. The mean maximum elapsed time between a single egg turning event for either species was $4.5-4.8 \mathrm{~h}$ and not statistically different $\left(F_{1,27}=0.12\right.$, $P=0.731$ ) between species (Table 3 ).

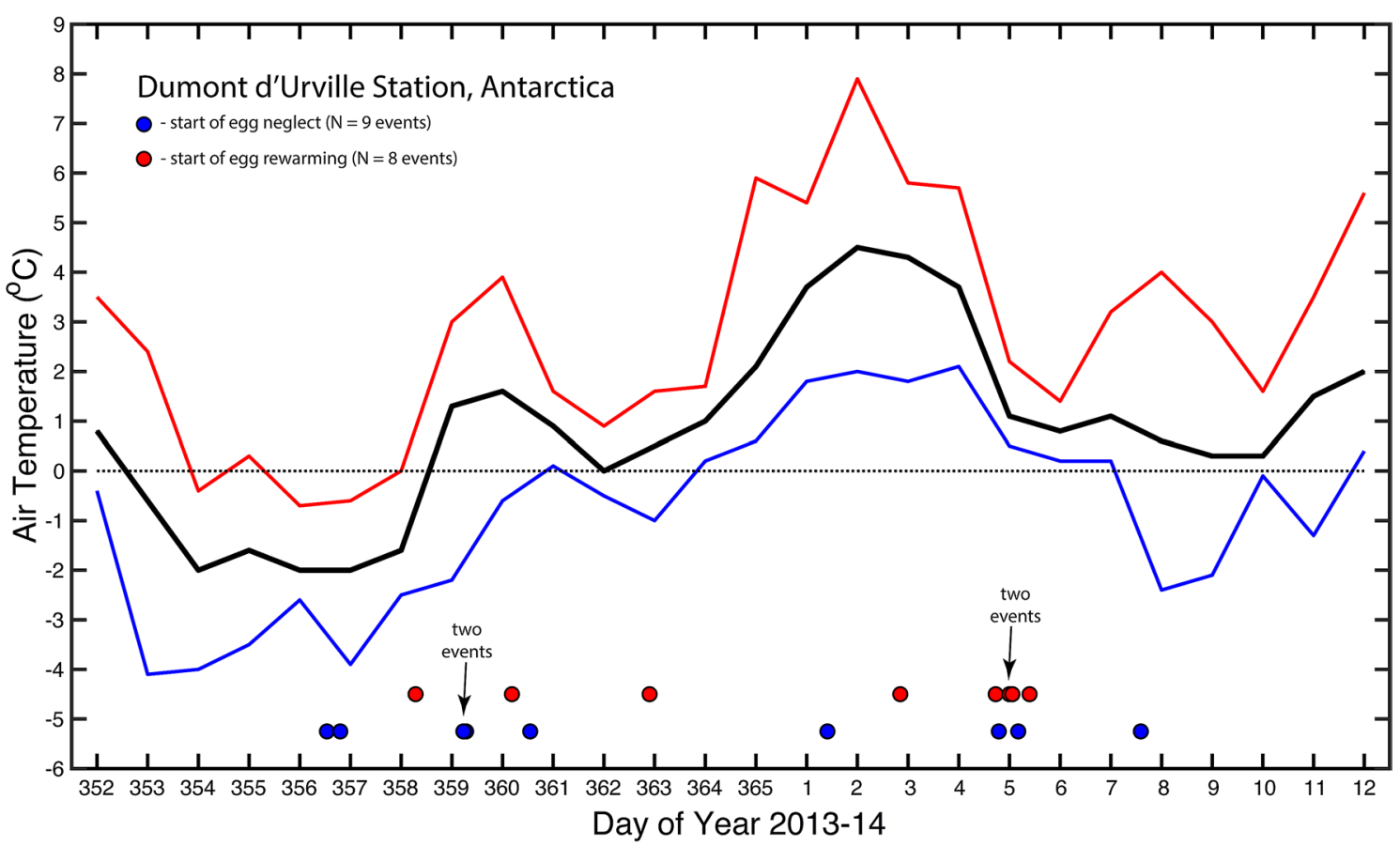

Fig. 4 Daily air temperatures measured by the Météo-France service at Dumont d'Urville Station, Antarctica in Dec 2013-Jan 2014. Mean values are shown in black, minimum in blue, maximum in red solid lines, and $0{ }^{\circ} \mathrm{C}$ is marked by the dotted line. The temporal period shown spans the duration when egg loggers were deployed in the nests of snow and Cape petrels. Blue symbols denote the start of an egg neglect event and red symbols indicate when incubation of unattended eggs resumed (snow petrels only)

Table 3 Egg turning patterns (mean \pm SD) of snow and Cape petrels breeding at Dumont d'Urville Station, Antarctica

\begin{tabular}{llllll}
\hline Species & $\mathbf{N}$ & $\begin{array}{l}\text { Egg turning rate (turns } \\
\mathbf{h}^{-1} \text { ) }\end{array}$ & Angle change per turn $\left(^{\circ}\right)$ & $\begin{array}{l}\text { Time between turns } \\
(\mathbf{m i n})\end{array}$ & $\begin{array}{l}\text { Max time } \\
\text { between turns } \\
(\mathbf{m i n})\end{array}$ \\
\hline Snow petrel & $15^{\mathrm{a}}$ & $1.31 \pm 0.33$ & $43.1 \pm 43.2$ & $36.0 \pm 11.0$ & $290 \pm 206$ \\
(min, max) & & $(0.82,1.81)$ & $(10,180)$ & $(17.1,53.1)$ & $(62,961)$ \\
Cape petrel & $14^{\mathrm{b}}$ & $1.38 \pm 0.39$ & $48.6 \pm 43.7$ & $42.5 \pm 13.7$ & $268 \pm 119$ \\
(min, max) & & $(0.76,2.03)$ & $(10,180)$ & $(26.1,74.9)$ & $(146,554)$ \\
\hline
\end{tabular}

Turning patterns were monitored using artificial eggs with data loggers recording changes in egg orientation at intervals of $1 \mathrm{~Hz}$. $\mathrm{N}$ is the number of nests that were evaluated for each parameter. Egg turning and angle changes per turn were based on the combined angular changes (i.e., roll, pitch, and yaw) in egg attitude [26]. Statistical comparisons revealed no significant difference between species for each parameter, except angle change per turn (see "Results")

${ }^{\text {a }}$ Two of 17 loggers had faulty accelerometers, but accurate temperature thermistors

${ }^{\mathrm{b}}$ One of 15 loggers had a faulty accelerometer, but accurate temperature thermistor 


\section{Discussion}

Here, we show that egg attendance patterns of both species were nearly identical in terms of egg turning rates and egg temperatures during periods of continuous incubation. We also observed several occurrences of egg neglect in snow petrels where egg temperatures cooled to within a few degrees above ambient air temperatures and eggs remained unturned until a parent returned to the nest and resumed incubation duties. In contrast, Cape petrels remained on their nests and incubated egg loggers continuously for the duration of each deployment. Overall, these results improve our understanding about the critical role of egg attendance behaviors in polar species and provide greater insight on the internal environment of avian eggs by proxy of a novel biologging tool.

\section{Potential effects on incubation behavior and hatching success}

Although we have no reason to believe that our egg manipulations caused aberrant parental behaviors during incubation in either species, the relatively low hatching success (36.4\% of fertile eggs returned) of snow petrels in our study was concerning. Indeed, snow petrels at Dumont d'Urville, and at multiple sites distributed around Antarctica, exhibit remarkable annual variability in hatching success $(11-88 \%[31,47])$ and overall breeding performance $(19-80 \%[31,47])$, which appears to be correlated with sea-ice extent $[45,47,48]$ and changing climate $[44,49]$. Our experimental group of snow petrel nests had comparable hatching success to unmanipulated snow petrel nests (60 of 163; 36.8\%). Furthermore, we observed no abandonments of Cape petrels incubating our loggers and all birds readily accepted and continued to incubate their original eggs up to the last nest check. Thus, we can conclude that our manipulations (e.g., egg swaps, nest checks) appeared to cause minimal disturbance to incubating birds in this study. Interestingly, the majority of seabirds at Dumont d'Urville in 2013-2014 experienced record lows in breeding performance associated with extensive sea-ice coverage and anomalous weather conditions in this Antarctic region [50,51].

We also determined that turning rates of eggs kept in the incubator $\left(0.25-0.33\right.$ turn $\left.\mathrm{h}^{-1}\right)$ were considerably lower than our field measurements of 1.31 turn $\mathrm{h}^{-1}$ (Table 3). Although expected, the incubator was not equipped to turn eggs automatically, rather eggs were turned by hand. Therefore, a lower turning frequency was chosen at the start of our experiment to minimize entry into the incubator to maintain its temperature. We also purposely kept the duration of egg logger deployments (and eggs incubated artificially) short $(<10 \%$ of a 45-47 day incubation period) to minimize impacts on developing embryos knowing that it was not feasible to mimic adult attendance behaviors. Nevertheless, it is reassuring that hatching success of manipulated eggs was comparable to eggs in unmanipulated nests.

\section{Egg temperatures of petrels and other seabirds}

An objective of the present study was to compare egg temperatures of snow and Cape petrels to each other and to published data from other seabird species. We determined that parents in both species incubated their eggs at $34.1{ }^{\circ} \mathrm{C}\left(\max 38-39{ }^{\circ} \mathrm{C}\right)$ even though snow petrels nest in crevices with greater protection from strong winds and buffering from wind chill and rain/snow. We also observed several instances of egg neglect in snow petrels, yet their egg temperatures were identical to those of Cape petrels after rewarming and continuous incubation. Egg temperature has a profound effect on embryonic development $[7,18-20]$ and when temperatures are periodically lowered (i.e., egg neglect), the incubation phase can be extended $[9,14,21]$. However, the duration of incubation for both species generally differs by only $1-2$ days on average [34-36]. Thus, we initially predicted egg temperatures to be slightly higher in snow petrels to compensate for periods of egg neglect, but this was not supported by the data.

Presently, few measurements of egg temperature have been reported for polar seabirds including five Antarctic species ([17, 20, 24, 52], this study) and one Arctic species $[41,53]$. For these species, mean egg temperatures range between 34.1 and $38.3^{\circ} \mathrm{C}$, with the lowest measurements obtained in the present study. When comparing only polar procellariiforms ( $N=4$ species), mean egg temperatures vary by $1.6^{\circ} \mathrm{C}$. Including additional measurements for other procellariiforms, regardless of environment, mean egg temperatures range between $29.6{ }^{\circ} \mathrm{C}$ for Cory's shearwater (Calonectris diomedea; [54]) and $37.5{ }^{\circ} \mathrm{C}$ for Laysan albatross (Phoebastria immutabilis; [26]) and the overall mean egg temperature is $33.4{ }^{\circ} \mathrm{C}(N=19$ species; calculated from published data $[14,20,26,55-61])$.

Informative as these comparisons may be for describing the internal environment of eggs across bird species, there are several reasons for caution. Firstly, most previous studies do not distinguish egg temperatures associated with a diurnal cycle, yet eggs can vary between day/ night by $1-3{ }^{\circ} \mathrm{C}$ in some species $[26,62]$. Indeed, we observed no diurnal pattern in the incubation behaviors of snow and Cape petrels (described below) or egg temperatures, but we might expect this given the long polar daylength. When feasible, future studies should measure egg attendance patterns over multiple days to capture variation between day/night egg temperatures. Secondly, egg temperatures measured in the field have been obtained using probes inserted into real eggs [20, 
55-57], biologging devices [24, 26, 42, 43, 60, 62], and more recently using thermal imaging [61]. Methodological differences are important to consider because thermal gradients are known to occur across the egg surface [2, 61, 63], a main reason eggs are turned. Our biologging eggs had a single thermistor in the egg center so measurements should be equivalent to core egg temperature. Nevertheless, future design changes will include multiple thermistors placed around the egg surface (sensu [22]) to capture thermal gradients with greater accuracy and precision.

\section{Egg neglect in snow petrels}

Egg neglect patterns in petrels is influenced by parental body condition [11], regulated by hormonal changes [38, 39 ], and largely driven by food availability, oceanic conditions, and sea-ice extent [31, 48-50]. The impacts of egg neglect on breeding performance results primarily in an extension of the incubation period $[9,11,14,17]$, and when durations of egg neglect are prolonged and/or events are frequent, breeding success declines $[9,14,17]$. At Dumont d'Urville, snow petrels left their eggs unattended for periods of 1-4 days (mean 1.34 days), which is comparable to other high-latitude petrel species $[9,11$, 17]. However, we lack colony-wide trends for the duration and/or frequency of egg neglect events because routine nest checks were only conducted for nests with loggers. Nevertheless, 7 of $29(24 \%)$ study nests had at least one egg neglect event and three nests had partial recordings of a second event. All study nests that exhibited egg neglect failed to hatch (one egg was infertile), so it is tempting to attribute this breeding failure to egg neglect. However, there were other study nests with fertile eggs, but no egg neglect that also failed. It is also possible that egg neglect occurred before logger deployments or after logger recovery, which went undetected. In the present study, we opted to characterize egg attendance in a cross section of the population rather than a longitudinal study. Future research will hopefully more fully explore this occurrence in snow petrels.

Despite its prevalence in crevice/burrow nesting seabirds, few studies have reported measurements of egg temperature during periods of neglect $[9,14,20,64]$. We determined that unattended snow petrel eggs decreased to an average of $5.5^{\circ} \mathrm{C}$, comparable to another Antarctic species $\left(5.8^{\circ} \mathrm{C}\right)$, the Wilson's storm petrel (Oceanites oceanicus; [20]). These egg temperatures are well below the 'physiological zero temperature' $\left(<25-27^{\circ} \mathrm{C}\right)$ where embryonic development is suspended (reviewed in [7, 65]). Nevertheless, rocky crevices where snow petrels nest provide some environmental buffer for unattended eggs because the lowest egg temperature $\left(1.8^{\circ} \mathrm{C}\right)$ was still above mean ambient air temperatures at the station (mean $0.9^{\circ} \mathrm{C}$, range -4.1 to $7.9^{\circ} \mathrm{C}$; Fig. 4 ).

Although egg loggers cannot mimic the exact thermal responses of natural eggs, calibrations in the lab show close agreement with temperature fluctuations in a controlled environment ([26] and S. Shaffer unpublished data). Thus, in addition to measuring minimum egg temperatures, we also approximated the rates of cooling and rewarming in snow petrel eggs (Table 2). Based on the elapsed time for temperatures to stabilize, eggs cooled at a slightly slower rate than when rewarmed by a parent, though differences were not statistically significant. However, these rate changes allowed us to estimate that a parental absence from the nest of only $34 \mathrm{~min}$ (i.e., [34.1$\left.25{ }^{\circ} \mathrm{C}=9.1{ }^{\circ} \mathrm{C}\right] / 0.27{ }^{\circ} \mathrm{C} \mathrm{min}{ }^{-1}$ ) is sufficient for an egg to cool enough that an embryo would reach 'physiological zero' $[7,65]$. If snow petrel embryos respond similarly to further reductions in temperature as shown in other petrel species $[18,20]$, metabolism would slow to near zero after approximately $90 \mathrm{~min}$ when neglected eggs reach $5.5^{\circ} \mathrm{C}$ (e.g., Fig. 3).

When returning to an unattended nest, parents encounter an egg that is generally $20-30{ }^{\circ} \mathrm{C}$ cooler than the one they left. Hence, the chilled egg becomes a heat sink that requires energy input from the parent to rewarm and we can model this interaction to estimate the cost of egg rewarming. Assuming a specific heat capacity of $3.13 \mathrm{~kJ} \mathrm{~kg}^{-1}{ }^{\circ} \mathrm{C}^{-1}$ for avian eggs [66], a $0.055 \mathrm{~kg}$ snow petrel egg (Table 1) warmed by the parent at $19.8^{\circ} \mathrm{C} \mathrm{h}^{-1}$ (i.e., $0.33{ }^{\circ} \mathrm{C} \mathrm{min}^{-1}$; Table 2) requires about $4.6 \mathrm{~kJ}$ over $75 \mathrm{~min}$ (or $3.6 \mathrm{~kJ} \mathrm{~h}^{-1}$ ) to restore egg temperature to $34{ }^{\circ} \mathrm{C}$. The metabolic rate of a 300-g adult snow petrel measured at $1{ }^{\circ} \mathrm{C}$ is $13.1 \mathrm{~kJ} \mathrm{~h}^{-1}\left([67,68]\right.$; BMR of 7.4 to $8.7 \mathrm{~kJ} \mathrm{~h}^{-1}$ adjusted to $1{ }^{\circ} \mathrm{C}$ using reported conductance in [67]). Combining egg rewarming costs and adult metabolic rate $\left(11.0\right.$ to $\left.16.7 \mathrm{~kJ} \mathrm{~h}^{-1}\right)$, an adult snow petrel would use 1.5 to $1.9 \times \mathrm{BMR}$ (depending on environmental temperature) to rewarm a chilled egg for approximately $75 \mathrm{~min}$. This approximation seems reasonable because incubation costs of other Procellariiformes range between 0.77 and $1.85 \times$ RMR (reviewed in [69]), but it is important to note that these latter studies were not specifically measuring egg rewarming costs, rather they reported the general cost of incubation.

\section{Egg attendance behavior in petrels and other seabirds}

A key element of egg attendance behavior in parent birds is egg turning and we determined that snow and Cape petrels turn their eggs at similar rates (Table 3; Fig. 2). Given the occurrence of egg neglect and its impact on egg temperatures (above), we predicted turning rates to be higher for snow petrels. Indeed, during periods of continuous incubation, the only species-specific difference 
measured was the angle change of the egg per turning event, which was $5^{\circ}$ greater in Cape petrels. It is difficult to evaluate the biological significance of these angles changes, but we can offer three possible explanations. Firstly, Cape petrels nest in the open on rocky slopes with greater exposure to environmental variations in wind and snow/rain. This might require parents to make greater egg orientation and/or body posture changes to accommodate weather conditions while attempting to keep the egg warmed more evenly. Alternatively, these differences may be the result of adults responding to skuas with greater or more frequent body posture changes and rotations about the nest to maintain vigilance. Finally, these patterns could be intrinsically different between petrel species based on unknown reasons.

A comparison of egg attendance patterns among seabirds generally reflects a wide variation in egg turning frequency ranging from 0.34 to 6.0 turns $\mathrm{h}^{-1}$ (reviewed in [5]). Unfortunately, a limited number of species have been studied so generalizations about specific patterns among clades are not really practical. Also, the manner in which egg turning behavior has been measured contributes to some of this variation including ethograms, frequent monitoring of changes in orientation of marked eggs in the nest, and more recently using biologging eggs. Given rapid changes in biologging technology, there has been more recent research on this topic (e.g., [24, 26, $41-43,52,62]$ ), which provides an opportunity to compare egg attendance patterns and associated life history characteristics among seabird species using similar technology (Fig. 5). Cursory comparisons reveal a pattern associated with breeding in the Antarctic environment where egg turning rates and egg temperatures are lower (petrels and penguin [24, 52]) contrasted by the Arctic black-legged kittiwake (Rissa tridactyla) with higher turning rates and egg temperatures $[41,53]$. Another trait common among four species (auklet, petrels, and albatross) is a clutch size of one egg, but patterns of egg turning and temperature could not be more different (Fig. 5). For example, the auklet turns its egg more frequently and incubates at higher temperatures [42] than both petrel species and the albatross exhibits a pattern more similar to the auklet $[26,43]$ even though it is closely related petrels and all three share prolonged incubation periods. Finally, birds from the order Charadriiformes have multiegg clutches (except auklet), shorter incubation periods, higher egg temperatures and the highest and lowest turning rates $[41-43,53,62]$.

As rudimentary as these comparisons maybe, they clearly indicate that more research is needed to clarify these patterns of egg attendance behavior in seabirds. Complementary studies on temperate and tropical

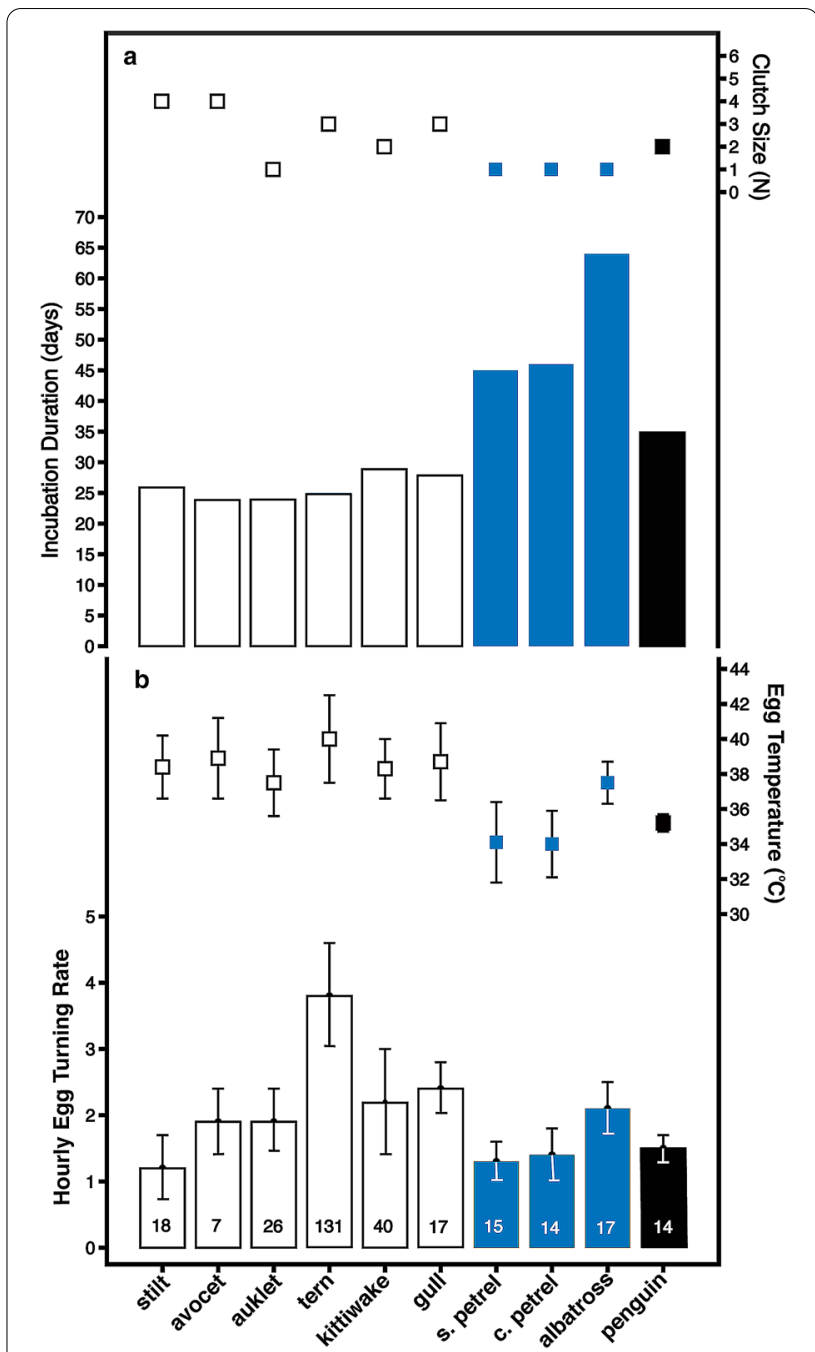

Fig. 5 Comparative incubation patterns of seabirds (and two waders) evaluated using the same type of egg loggers for each species. The unfilled bars and symbols represent birds from Charadriiformes, blue bars and symbols from Procellariiformes, and black bars and symbols from Sphenisciformes. Sample sizes for data presented in pane B are given inside each bar. The original sources of data for (1) stilt and avocet are from G.T. Taylor unpublished, and tern are from [62]; (2) auklet, gull, and albatross are from [26]; (3) kittiwake from [41, 53]; (4) both s. petrel and C. petrel are from the present study; (5) penguin from $[25,52]$

petrels would be useful to evaluate the influence of environment across this clade, as would additional data on polar species with single egg clutch sizes (e.g., murres, little auks, fulmars). Lastly, we are unaware of any published studies using biologging devices to investigate egg attendance patterns in Pelecaniforms, which are a diverse clade with wide geographic distribution and variable life history patterns. 


\section{Conclusions}

A key difference in the breeding ecology of snow and Cape petrels at Dumont d'Urville is the use of crevice nesting by snow petrels, which allows them to leave the nest temporarily to bathe, drink, or forage. An obvious benefit of crevice nesting is protection of the neglected egg from predators and environmental variation, which is not possible for Cape petrels that nest on open cliffs. Thus, we expected to see greater differences in egg attendance patterns between petrel species because one uses egg neglect and the other does not, even though durations of the incubation period are similar (45 vs. 47 days [34-36], respectively). Indeed, egg turning rates and egg temperatures were nearly identical, when excluding periods of egg neglect in snow petrels. Given that egg neglect extends the incubation phase, it would be interesting to test whether all snow petrels use egg neglect, and if not, whether incubation durations are shortened by continuous egg attendance. This would require a time intensive monitoring effort with the potential to cause significant disturbance. However, with modifications in power consumption, extended battery life, and increased memory capacity, our biologging devices could be an ideal tool to conduct a longitudinal study covering the complete incubation cycle of both petrel species. This would allow a complete characterization of egg neglect in a polar petrel species.

The utility of biologging technology cannot be overstated because we were able to record the behavior of birds in an extreme environment with minimal disturbance. Finally, the results allowed us to add two more species to the list of previous studies using similar technology to make rudimentary comparisons that highlight areas of need for this field of biologging science.

\section{Acknowledgements}

We thank the captain and crew of the R/V Astrolabe for safe passage to Dumont d'Urville Station and logistical support provided by the Institut Polaire Français.

\section{Authors' contributions}

The study was conceived and designed by SAS and HW, executed in the field by SAS, PB, and CB. Funding and logistics were organized by HW, data analyzed by SAS, and writing and editing were performed by all authors. All authors read and approved the final manuscript.

\section{Funding}

This study was supported in part by Grants from the California State University Program for Education and Research in Biotechnology (CSUPERB) and SJSU RSCA program, awarded to SAS. Travel and logistical support were provided by the Institut Polaire Français Paul-Emile Victor (IPEV, programme n¹09, HW).

\section{Availability of data and materials}

All raw and analyzed data generated from the current study, as well as MAT$L A B$ codes used for data analysis in the current study, are available from the authors upon reasonable request.

\section{Declarations}

Ethics approval and consent to participate

Animal handling protocols were approved by the San Jose State University, Institutional Animal Care and Use Committee (No. 1000) and the Ethics Committee of IPEV.

\section{Consent for publication}

Not applicable.

\section{Competing interests}

The authors declare that they have no competing interests.

\section{Author details}

${ }^{1}$ Department of Biological Sciences, San Jose State University, One Washington Square, San Jose, CA 95192-0100, USA. ${ }^{2}$ Centre D'Etudes Biologiques de Chizé (CEBC), UMR 7372 CNRS- Université de La Rochelle, 79360 Villiers-en-Bois, France. ${ }^{3}$ Akvaplan-Niva AS, Fram Centre, 9296 Tromsø, Norway.

Received: 11 February 2021 Accepted: 11 May 2021

Published online: 20 May 2021

\section{References}

1. Deeming DC. How does the bird-nest incubation unit work? Avian Biol Res. 2016;9:103-13.

2. Turner J. Maintenance of egg temperature. Avian Incubation. Oxford: Oxford University Press; 2002. p. 119-42.

3. Deeming DC, Mainwaring MC. Functional properties of nests. In: Deeming DC, Reynolds SJ, editors. Nests eggs incubation. Oxford: Oxford University Press; 2015. p. 29-49.

4. Tullett S, Deeming D. Failure to turn eggs during incubation: effects on embryo weight, development of the chorioallantois and absorption of albumen. Br Poult Sci. 1987:28:239-43.

5. Deeming D. Patterns and significance of egg turning. Avian Incubation. Oxford: Oxford University Press; 2002. p. 161-78.

6. Deeming DC. The role of egg turning during incubation. Avian Biol Res. 2009;2:67-71.

7. Webb DR. Thermal tolerance of avian embryos: a review. Condor. 1987;89:874.

8. Bueno-Enciso J, Barrientos R, Ferrer ES, Sanz JJ. Do extended incubation recesses carry fitness costs in two cavity-nesting birds? J Field Ornithol. 2017:88:146-55.

9. Boersma PD, Wheelwright NT. Egg neglect in the procellariiformes: reproductive adaptations in the Fork-Tailed Storm-Petrel. Condor. 1979;81:157.

10. Shoji A, Elliott KH, Aris-Brosou S, Crump D, Gaston AJ. Incubation patterns in a Central-Place Forager affect lifetime reproductive success: scaling of patterns from a foraging bout to a lifetime. PLoS ONE. 2011;6:e17760.

11. Chaurand T, Weimerskirch $\mathrm{H}$. Incubation routine, body mass regulation and egg neglect in the Blue Petrel Halobaena caerulea. Ibis. 1994;136:285-90.

12. Croston R, Hartman CA, Herzog MP, Casazza ML, Feldheim CL, Ackerman JT. Timing, frequency, and duration of incubation recesses in dabbling ducks. Ecol Evol. 2020;10:2513-29.

13. Zhang L, An B, Shu M, Zhao C, Yang X, Suo Y, Se Y, Dabu X. Incubation strategies of the Black-necked Crane (Grus nigricollis) in relation to ambient temperature and time of day. Avian Res. 2017:8:19.

14. Boersma PD. Why some birds take so long to hatch. Am Nat. 1982;120:733-50.

15. Ronconi RA, Hipfner JM. Egg neglect under risk of predation in Cassin's Auklet (Ptychoramphus aleuticus). Can J Zool. 2009;87:415-21.

16. Gaston AJ, Powell DW. Natural incubation, egg neglect, and hatchability in the ancient murrelet. Auk. 1989;106:433-8.

17. Pefaur JE. Egg-neglect in the Wilson's storm petrel. Wilson Bull. 1974:86:16-22.

18. Vleck CM, Kenagy GJ. Embryonic Metabolism of the fork-tailed storm petrel: physiological patterns during prolonged and interrupted incubation. Physiol Zool. 1980;53:32-42. 
19. Olson CR, Vleck CM, Vleck D. Periodic cooling of bird eggs reduces embryonic growth efficiency. Physiol Biochem Zool. 2006;79:927-36.

20. Williams JB, Ricklefs RE. Egg temperature and embryo metabolism in some high-latitude Procellariiform birds. Physiol Zool. 1984;57:118-27.

21. Johnstone RM, Davis LS. Incubation routines and foraging-trip regulation in the Grey-faced Petrel Pterodroma macroptera gouldi. Ibis. 1990;132:14-20.

22. Howey P, Board RG, Davis DH, Kear J. The microclimate of the nests of waterfowl. Ibis. 1984;126:16-32.

23. Boone RB, Mesecar RS III. Telemetric egg for use in egg-turning studies. J Field Ornithol. 1989;60:315-22.

24. Beaulieu M, Thierry A-M, Handrich Y, Massemin S, Le Maho Y, Ancel A. Adverse effects of instrumentation in incubating Adélie penguins (Pygoscelis adeliae). Polar Biol. 2010:33:485-92.

25. Thierry A-M, Massemin S, Handrich Y, Raclot T. Elevated corticosterone levels and severe weather conditions decrease parental investment of incubating Adélie penguins. Horm Behav. 2013;63:475-83.

26. Shaffer SA, Clatterbuck CA, Kelsey EC, Naiman AD, Young LC, VanderWerf EA, et al. As the egg turns: monitoring egg attendance behavior in wild birds using novel data logging technology. PLoS ONE. 2014;9:e97898.

27. Warham J. The petrels: their ecology and breeding systems. London: A\&C Black; 1990.

28. Marchant S, Higgins P. Handbook of Australian, New Zealand and Antarctic Birds. Melbourne: Oxford University Press; 1990.

29. Croxall JP, Steele WK, McInnes SJ, Prince PA. Breeding distribution of the snow petrel Pagodroma nivea. Mar Ornithol. 1995;23:69-99.

30. Olivier F, Lee AV, Woehler EJ. Distribution and abundance of snow petrels Pagodroma nivea in the Windmill Islands, East Antarctica. Polar Biol. 2004;27:257-65

31. Chastel $\mathrm{O}$, Weimerskirch $\mathrm{H}$, Jouventin P. High annual variability in reproductive success and survival of an Antarctic seabird, the snow petrel Pagodroma nivea: a 27-year study. Oecologia. 1993;94:278-85.

32. Weidinger K. Incubation and brooding rhythm of the Cape Petrel Daption capense at Nelson Island, South Shetland Islands, Antarctica. Ibis. 2008;140:163-70.

33. Amundsen T. Egg size and early nestling growth in the snow petrel. Condor. 1995;97:345-51.

34. Mougin JL. Etude écologique de quatres espèces de pétrel antarctiques. Oiseau Rev Fr Ornithol. 1968:38:1-52.

35. Hodum PJ. Breeding biology of high-latitude Antarctic fulmarine petrels (Procellariidae). J Zool. 2002;256:139-49.

36. Weidinger K. Breeding cycle of the Cape petrel Daption capense at Nelson Island, Antarctica. Polar Biol. 1997:17:469-72.

37. Angelier F, Moe B, Weimerskirch $\mathrm{H}$, Chastel $\mathrm{O}$. Age-specific reproductive success in a long-lived bird: do older parents resist stress better? J Anim Ecol. 2007;76:1181-91.

38. Angelier F, Moe B, Blanc S, Chastel O. What factors drive prolactin and corticosterone responses to stress in a long-lived bird species (snow Petrel Pagodroma nivea)? Physiol Biochem Zool. 2009;82:590-602.

39. Angelier F, Wingfield JC, Parenteau C, Pellé M, Chastel O. Does short-term fasting lead to stressed-out parents? A study of incubation commitment and the hormonal stress responses and recoveries in snow petrels. Horm Behav. 2015;67:28-37.

40. Tartu S, Angelier F, Wingfield JC, Bustamante P, Labadie P, Budzinski H, et al. Corticosterone, prolactin and egg neglect behavior in relation to mercury and legacy POPs in a long-lived Antarctic bird. Sci Total Environ. 2015;505:180-8

41. Blévin P, Shaffer SA, Bustamante P, Angelier F, Picard B, Herzke D, et al. Organochlorines, perfluoroalkyl substances, mercury, and egg incubation temperature in an Arctic seabird: insights from data loggers: contaminants and parental care in Arctic seabirds. Environ Toxicol Chem. 2018;37:2881-94.

42. Kelsey EC, Bradley RW, Warzybok P, Jahncke J, Shaffer SA. Environmental temperatures, artificial nests, and incubation of Cassin's auklet. J Wildl Manag. 2016;80:292-9.

43. Clatterbuck CA, Young LC, VanderWerf EA, Naiman AD, Bower GC, Shaffer SA. Data loggers in artificial eggs reveal that egg-turning behavior varies on multiple ecological scales in seabirds. Auk. 2017;134:432-42.

44. Barbraud C, Weimerskirch H. Antarctic birds breed later in response to climate change. Proc Natl Acad Sci. 2006;103:6248-51.

45. Jenouvrier S, Barbraud C, Weimerskirch H. Long-term contrasted responses to climate of two Antarctic seabird species. Ecology. 2005;86:2889-903.
46. Pinheiro J, Bates D. Mixed-effects models in S and S-PLUS. New York: Springer; 2000 .

47. Olivier F, van Franeker JA, Creuwels JCS, Woehler EJ. Variations of snow petrel breeding success in relation to sea-ice extent: detecting local response to large-scale processes? Polar Biol. 2005;28:687-99.

48. Barbraud C, Weimerskirch $\mathrm{H}$. Contrasting effects of the extent of sea-ice on the breeding performance of an Antarctic top predator, the Snow Petrel Pagodroma nivea. J Avian Biol. 2001;32:297-302.

49. Jenouvrier S, Weimerskirch H, Barbraud C, Park Y-H, Cazelles B. Evidence of a shift in the cyclicity of Antarctic seabird dynamics linked to climate. Proc $R$ Soc B Biol Sci. 2005;272:887-95.

50. Barbraud C, Delord K, Weimerskirch H. Extreme ecological response of a seabird community to unprecedented sea ice cover. R Soc Open Sci. 2015:2:140456.

51. Ropert-Coudert Y, Kato A, Meyer X, Pellé M, Maclntosh AJJ, Angelier F, et al. A complete breeding failure in an Adélie penguin colony correlates with unusual and extreme environmental events. Ecography. 2015;38:111-3.

52. Thierry A-M, Brajon S, Massemin S, Handrich Y, Chastel O, Raclot T. Decreased prolactin levels reduce parental commitment, egg temperatures, and breeding success of incubating male Adélie penguins. Horm Behav. 2013;64:737-47.

53. Blévin P, Shaffer SA, Bustamante P, Angelier F, Picard B, Herzke D, et al. Contaminants, prolactin and parental care in an Arctic seabird: contrasted associations of perfluoroalkyl substances and organochlorine compounds with egg-turning behavior. Gen Comp Endocrinol. 2020;291:113420.

54. Wink M, Scharlau W, Ristow D. Niedrige Ei-und Körpertemperatur ("Hypothermie") bei brütenden Gelbschnabelsturmtauchern (Calonectris diomedea). J Für Ornithol. 1987;128:334-8.

55. Ricklefs RE, Rahn H. The incubation temperature of leach's storm-petrel. Auk. 1979;96:625-7.

56. Grant GS, Pettit TN, Rahn H, Whittow GC, Paganelli CV. Water loss from Laysan and black-footed Albatross eggs. Physiol Zool. 1982;55:405-14.

57. Grant GS, Pettit TN, Rahn H, Whittow GC, Paganelli CV. Regulation of water loss from Bonin petrel (Pterodroma hypoleuca) eggs. Auk. 1982;99:236-42.

58. Howell TR, Bartholomew GA. Temperature regulation in Laysan and blackfooted Albatrosses. Condor. 1961;63:185-97.

59. Howell TR, Bartholomew GA. Temperature regulation in nesting bonin Island petrels, wedge-tailed Shearwaters, and Christmas Island Shearwaters. Auk. 1961;78:343-54.

60. Brown CR, Adams NJ. Egg temperature, embryonic metabolism, and water loss from the eggs of subantarctic Procellariiformes. Physiol Zool. 1988;61:126-36.

61. Boersch-Supan PH, Johnson LR, Phillips RA, Ryan SJ. Surface temperatures of albatross eggs and nests. Emu Austral Ornithol. 2018;118:224-9.

62. Taylor GT, Ackerman JT, Shaffer SA. Egg turning behavior and incubation temperature in Forster's terns in relation to mercury contamination. PLoS ONE. 2018;13:e0191390.

63. Drent RH. Functional aspects of incubation in the herring gull. Behav Suppl. 1970:17:1-132.

64. Blight LK, Bertram DF, Williams TD, Cowen L. Interannual variation in egg neglect and incubation routine of rhinoceros auklets Cerorhinca monocerata during the 1998-1999 El Niño/La Niña events. Mar Ornithol. 2010;38:11-5.

65. Haftorn S. Incubating female passerines do not let the egg temperature fall below the "Physiological Zero Temperature" during their absences from the nest. Ornis Scand. 1988:19:97.

66. Romanoff AL, Romanoff AJ. The Avian egg. Ithaca: Cornell University; 1949.

67. Weathers WW, Gerhart KL, Hodum PJ. Thermoregulation in Antarctic fulmarine petrels. J Comp Physiol. 2000;170:561-72.

68. Moe B, Angelier F, Bech C, Chastel O. Is basal metabolic rate influenced by age in a long-lived seabird, the snow petrel? J Exp Biol. 2007;210:3407-14

69. Whittow GC, Schreiber E, Burger J. Seabird reproductive physiology and energetics. In: Biology of Marine Birds. Boca Raton: CRC Press; 2002. p. 409-37.

\section{Publisher's Note}

Springer Nature remains neutral with regard to jurisdictional claims in published maps and institutional affiliations. 